Article

\title{
Design of the OffWindChina 5 MW Wind Turbine Rotor
}

\author{
Zhenye Sun ${ }^{1}$, Matias Sessarego ${ }^{2}$, Jin Chen ${ }^{1}$ and Wen Zhong Shen ${ }^{2, *}$ \\ 1 State Key Laboratory of Mechanical Transmission, Chongqing University, Chongqing 400044, China; \\ zhenye_sun@163.com (Z.S.); chenjin413@cqu.edu.cn (J.C.) \\ 2 Department of Wind Energy, Fluid Mechanics Section, Technical University of Denmark, Nils Koppels Allé, \\ Building 403, Lyngby 2800, Denmark; matse@dtu.dk \\ * Correspondence: wzsh@dtu.dk; Tel.: +45-4525-4317
}

Academic Editor: Lance Manuel

Received: 5 March 2017; Accepted: 30 May 2017; Published: 3 June 2017

\begin{abstract}
The current article describes the conceptual design of a rotor for a $5 \mathrm{MW}$ machine situated at an offshore site in China (OffWindChina). The OffWindChina 5 MW rotor design work was divided into two parts between the Technical University of Denmark (DTU) and the Chong Qing University (CQU). The two parts consist of the aeroelastic and structural design phases. The aeroelastic part determines the optimal outer blade shape in terms of cost of energy (COE), while the structural part determines the internal laminate layup to achieve a minimum blade mass. Each part is performed sequentially using in-house optimization tools developed at DTU and CQU. The designed blade yields a high energy output while maintaining the structural feasibility with respect to international standards.
\end{abstract}

Keywords: wind energy; wind turbine blade design; aeroelastic blade design; finite-element analysis; site-specific design

\section{Introduction}

China is the largest overall wind energy market in the world since 2009 [1]. In 2015, China added $30.8 \mathrm{GW}$ of new wind power capacity to the grid, the highest annual added capacity for any country [2]. China has abundant wind resources both onshore and offshore [3]. The most abundant offshore wind resource is in the southeastern coast of China [4], but the cost of offshore wind energy is more expensive than that of onshore wind energy. In addition, the coastal wind conditions in China, where one such typical condition is the tropical cyclone typhoon, are different from the rest of the world $[5,6]$. Offshore wind energy has many advantages over its onshore counterpart, such as a higher relative inflow velocity and lower inflow turbulence [7], and the low requirement of noise and visual pollution controls [8]. For more detailed characteristics about offshore wind energy, the reader is referred to the publications [9-11].

The design of wind turbine blades consists of aerodynamic/aeroelastic design and structural design, and there are many publications in the literature about blade design. Chehouri et al. [12] provided a comprehensive review of the performance optimization techniques applied to wind turbine design. As these two aspects are tightly coupled, the optimization objective should be the cost of energy (COE), which is defined as the ratio between the annual energy production (AEP) and the total cost. The total cost includes the capital cost, balance of station and operational costs. For site specific design, AEP is calculated by the site specific wind speed probability distribution and the turbine specific power versus speed distribution. For a given site, where the wind speed probability distribution is fixed, AEP only relates to the turbine specific power curve. When considering a same rated power (for example $5 \mathrm{MW}$ ) and neglecting the energy losses, the wind turbine power relates 
to the rotor radius square and the rotor power coefficient. The power coefficient relates to the airfoil shape, chord and twist distributions, and the rotor radius. From the rotor structural side, the rotor mass increases cubically or sub-cubically with the rotor radius [13]. Thus, the rotor radius is very important for $\mathrm{COE}$ and should be considered as a design variable. Fuglsang et al. [14] pointed out that the rotor diameter is more important than the aerodynamic shape. Wang et al. [15] optimized the chord and twist distributions of several turbines with the objective of minimum COE. Richard [16] optimized the airfoils together with the blade chord and twist distributions with minimum COE. However, they did not optimize the rotor radius. Moreover, they used the power production load cases with a steady wind in both aerodynamic and structural calculations. However, the structure should be examined under various load cases, which should not be limited to the power production loads. Fuglsang and Thomsen [17] optimized 1.5-2.0 MW stall-regulated wind turbines with the aim of minimum COE and considered the load cases including the normal production and a fault condition (error in the yawing mechanism). They only optimized the overall wind turbine parameters, such as rotor diameter, rated power and hub height, etc.

There are many publications demonstrating different methodologies for blade structure optimization. Barnes et al. [18] optimized the blade structure with variations of internal geometry configuration, such as the shear webs span-wise location and chord-wise location of spar. The single shear web design is also investigated and their results show that the single web configuration has a smaller torsional deflection with almost the same mass reduction as that of the two webs configuration. Jureczko et al. [19] optimized the shell thickness, web thickness, number of stiffening ribs and arrangement of stiffening ribs. They mentioned that the spar should be twisted rather than straight. The twist distribution of the spar was optimized in [19]. Buckney et al. [20] utilized topology optimization techniques on a $45 \mathrm{~m}$ wind turbine blade and found that the trailing edge reinforcement and the offset spar cap topology are very important for maximizing stiffness and minimizing stress. The optimized spar has a position offset from the point of maximum thickness and the upper spar cap (suction side) moves towards the trailing edge. A similar spar position offset can be seen in [21]. These findings also convinced the authors of the current article to optimize the twist distribution of the spar.

The current article aims to design wind turbine blades under offshore conditions in China. Researchers and academics who have designed wind turbine blades in China include Liu et al. [22,23], Gutierez [24], and Zhu et al. [25]. Liu et al. redesigned rotor blades for a $600 \mathrm{~kW}$ [22] and for a 1.3 MW [23] stall-regulated wind turbines situated on Nan'ao Island in Guangdong Province. Gutierez [24] designed a 2 MW variable-speed variable-pitch wind turbine in collaboration with Ming Yang Wind Power for a site in Guizhou Province in the southwest of China. Zhu et al. [25] redesigned a 1.5 MW turbine for inland China using an integrated aerodynamic and structural multi-objective optimization code.

The present article describes the work performed in a Sino-Danish collaborative project on reducing the cost of offshore wind energy by designing optimal wind turbines under the prevailing offshore wind conditions in China. The project involves the extension and application of the existing computational aerodynamic and structural design tools for wind turbine blade design at the Technical University of Denmark (DTU) and Chong Qing University (CQU) in China. The purpose of this research collaboration between the Danish and Chinese experts in wind turbine aerodynamics, structures, optimization and control, is to develop an integrated approach to capture optimally the offshore wind energy resources in China. Due to the nature of the project, the wind turbine designed in the current study is named as OffWindChina $5 \mathrm{MW}$. The current article is organized as follows: first, the aeroelastic component of the blade design is presented, which includes a description of the wind site data, optimization problem, numerical tools and results. This part is used to determine the optimal outer blade shape in terms of COE, with a simple structural design tool. The second part is the detailed structural design component utilizing the finite element method (FEM) and contains a description of 
the structural layup, optimization problem, numerical tools, and results. Finally, conclusions are given to summarize the obtained results.

\section{Aeroelastic Design}

The present section on the aeroelastic design of the OffWindChina $5 \mathrm{MW}$ rotor consists of four subsections: (1) Wind Site Data, (2) Problem Formulation, (3) Numerical Tools, and (4) Blade Design Results.

\subsection{Wind Site Data}

The wind turbine rotor is to be designed for an offshore site on the southeastern coast of China near the city of Shanghai and Jiangsu Province. Reference [26] contains normal and extreme wind conditions data at 12 coastal locations along China's coastline: Changhai, Xingcheng, Changdao, Chengshantou, Qingdao, Lüshi, Shengshi, Dachendao, Pingtan, Nanao, Shangchuandao, and Xisha. Reference [26] contains a figure that depicts the 12 locations within a geographical map of China's coastline.

The data contained in the reference are based on daily meteorological data measured at $10 \mathrm{~m}$ height above ground for periods of 40-62 years. The reference also contains a statistical analysis on the data. For example, Weibull and lognormal probability distributions were applied to fit the yearly wind speeds. Reference [26] contains a table with Weibull parameters for the 12 coastal locations as well. The coastal location of Shengshi was chosen for the present wind turbine rotor design study, since it lies the closest to Shanghai and does not experience typhoons as much as the southern coastal locations in China.

The probability density function of wind speed is a function that describes the relative likelihood for wind speed to take on a given value. The probability density function $f(v)$ of the Weibull distribution is:

$$
f(v)=\frac{k}{c}\left(\frac{v}{c}\right)^{k-1} \exp \left[-\left(\frac{v}{c}\right)^{k}\right]
$$

where $v$ is the wind speed in meter per second, $k(>0)$ is the dimensionless Weibull shape parameter, and $c(>0)$ is the scale parameter in meter per second. The Weibull distribution for Shengshi is shown in Figure 1. The cumulative distribution function of the Weibull distribution is:

$$
F(v)=1-\exp \left[-\left(\frac{v}{c}\right)^{k}\right]
$$

Since the Weibull parameters from [26] are based on measurements from $10 \mathrm{~m}$ above ground, an extrapolation is required to estimate the Weibull parameters for a turbine hub height of approximately $90 \mathrm{~m}$. Inverse transformations sampling with Equation (2) are used to extract the wind speeds. Next, the wind speeds are extrapolated to $90 \mathrm{~m}$ using the logarithmic law:

$$
v_{2}=v_{1} \frac{\ln \left(h_{2} / z_{0}\right)}{\ln \left(h_{1} / z_{0}\right)}
$$

where $v_{2}$ is the estimated wind speed at the hub height $h_{2}$. The wind speed $v_{1}$ is obtained from the inverse transformation sampling and $h_{1}$ is the reference height of $10 \mathrm{~m}$. A roughness length of $z_{0}=0.001$ is selected, which corresponds to the roughness length scale on sea surface [27]. The wind speed $v_{2}$ is placed into bins of width 0.5 from 0 to $25 \mathrm{~m} / \mathrm{s}$. A Weibull probability distribution is then fitted to obtain the Weibull parameters $k=2.4694$ and $c=9.4925$ at $h_{2}$, see Figure 1 . 


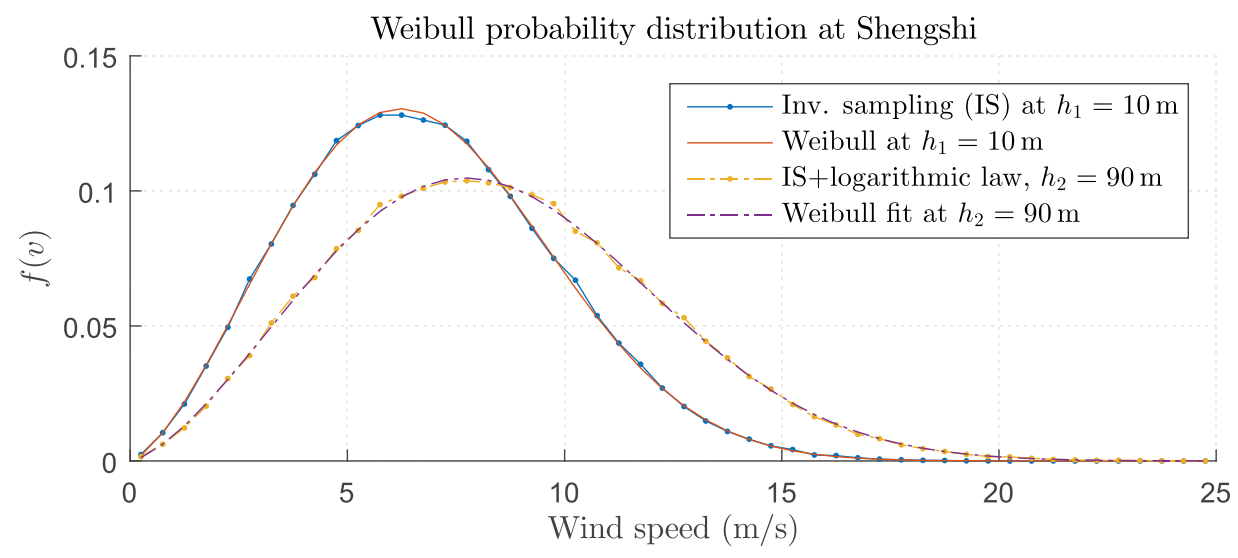

Figure 1. Measured and estimated Weibull probability distributions at Shengshi at heights of $10 \mathrm{~m}$ and $90 \mathrm{~m}$, respectively.

The average wind speed of the site, $V_{\mathrm{avg}}$, is computed as:

$$
V_{\text {avg }}=\int f(v) v \mathrm{~d} v
$$

which results in an average wind speed of $8.4194 \mathrm{~m} / \mathrm{s}$ for the Weibull probability distribution at Shengshi. Based on $V_{\text {avg }}=8.4194 \mathrm{~m} / \mathrm{s}$, and because the site is offshore and the turbulence intensity is low compared to onshore cases, a Class IIC turbine from IEC 61400-1 [28] is selected for the rotor design.

\subsection{Problem Formulation}

The design objective is to minimize COE:

$$
\begin{array}{cl}
\underset{x}{\operatorname{minimize}} & \frac{\mathrm{COE}}{\mathrm{COE}_{\text {ref }}} \\
\text { subject to } & \mathbf{x} \in \mathbb{R}^{n}, \\
& g_{c}(\mathbf{x}) \leq 0 \\
& x_{k}^{L} \leq x_{k} \leq x_{k}^{U}, k=1, \ldots, n
\end{array}
$$

where the subscript ref denotes the reference (or baseline) blade. The vector $x$ contains a total of $n$ variables that are real numbers, $\mathbb{R}^{n}$. The design variables, $\mathbf{x}=\left[x_{1}, x_{2}, \ldots, x_{n}\right]$, are control points (CPs) that define the chord, twist and relative thickness as a function of blade span, see Figure 2. B-splines [29] are used to parameterize the chord and twist distributions, while a linear interpolation is used for the relative thickness distribution. Only four CPs for the chord, two CPs for the twist, and two CPs for the relative thickness distribution are optimized. The total number of variables is then eight. In Figure 2, the CPs for chord vary vertically (i.e., increasing/decreasing chord) and are fixed radially, except for the first $\mathrm{CP}$ in the root region. The first $\mathrm{CP}$ varies radially but is not fixed vertically. The chord value for the first $\mathrm{CP}$ is equal to the minimum chord value needed to achieve a dimensional thickness similar to the baseline blade. CPs for the twist vary vertically and are fixed radially and vice-versa for the relative thickness CPs. The upper $(U)$ and lower $(L)$ notations, $x_{k}^{L} \leq x_{k} \leq x_{k}^{U}$, are the upper and lower limits of the CPs, while the non-linear inequality constraint, $g_{c} \leq 0$, is to promote monotonically decreasing chord, twist, and relative thickness at the outboard of the blade. The boundary and non-linear inequality constraints are required to ensure feasible blade designs. 


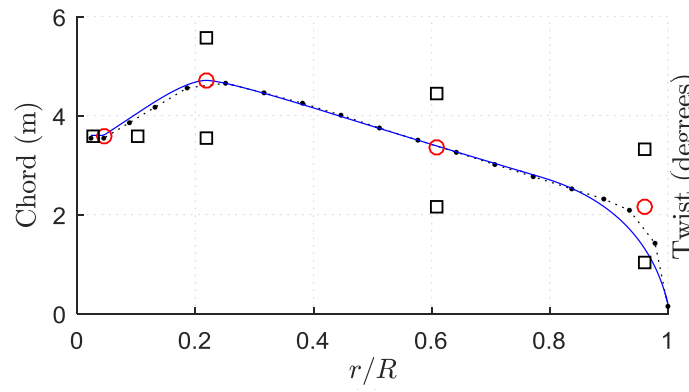

(a)

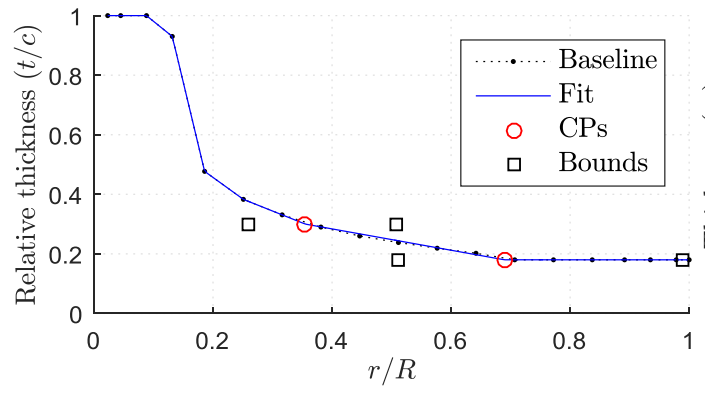

(c)

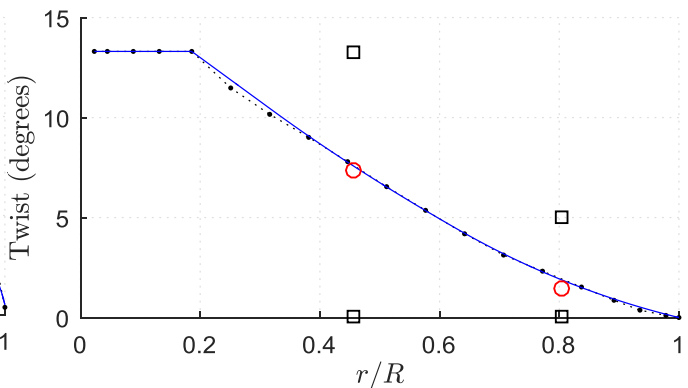

(b)

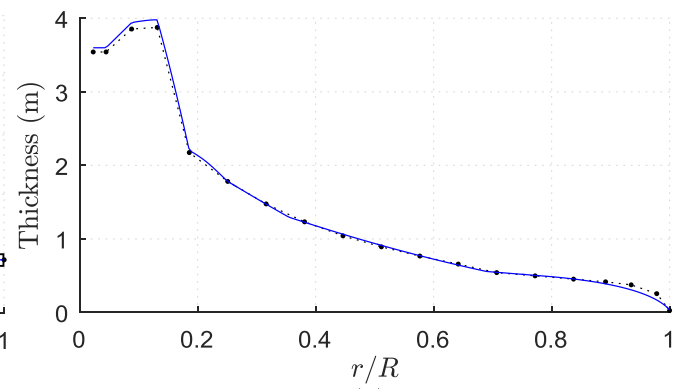

(d)

Figure 2. (a) Chord; (b) twist; (c) relative thickness; and (d) thickness fitted to the NREL 5 MW baseline wind turbine [30], where $r / R$ is the normalized blade radius.

A reference blade is required for the blade design and the one from the National Renewable Energy Laboratory (NREL) $5 \mathrm{MW}$ [30] was chosen for this purpose. Only the blade span-wise chord, twist, and relative thickness distributions from the NREL 5 MW rotor are used as reference values. Figure 2 depicts the chord, twist and relative thickness distributions of NREL 5 MW as well as best-fit curves using B-splines denoted as "Baseline" and "Fit", respectively.

The airfoils used for the blade design is comprised of DTU airfoils (DTU and DTU-LN2xx), the DU-W-405LM airfoil [30], and a cylinder for the root section. Figure 3 depicts the airfoil profile coordinates used in the blade design. The lift and drag coefficients for the profiles were computed using the quasi-three-dimensional unsteady viscous-inviscid interactive code ( $Q^{3}$ UIC) [31], see Figure 4 . A smoothing spline was applied on the lift and drag coefficients to remove the jagged results in the stall region from the $\mathrm{Q}^{3}$ UIC computations. Then, as shown in Figure 4, the Viterna extrapolation [32] was performed to obtain the lift and drag coefficients for $-180^{\circ}-180^{\circ}$ angles of attack. The airfoil data was then suitable for use in the aeroelastic tools described in the next sections.

\subsection{Numerical Tools}

Following [13], COE is calculated as:

$$
\mathrm{COE}=\frac{\mathrm{FCR} *(\mathrm{TCC}+\mathrm{BOS})+\mathrm{AOE}}{\mathrm{AEP}}
$$

where FCR is the fixed charge rate, TCC is the turbine capital cost, BOS is the balance of station, AOE is the annual operating expenses, and AEP is the annual energy production. FCR, TCC, and BOS are obtained from the NREL Wind Turbine Design Cost and Scaling Model [13]. Note AOE was neglected because it gives an incentive to reduce AEP, see underlying equations in [13]. FLEX5 [33] and the Weibull probability distribution at Shengshi are used to compute AEP, while a code based on the classical laminate theory called PreComp [34] to compute the blade stiffness and mass distributions. The contribution of the three blades in the rotor mass was computed from PreComp instead of the scaling law in [13] to estimate TCC. 


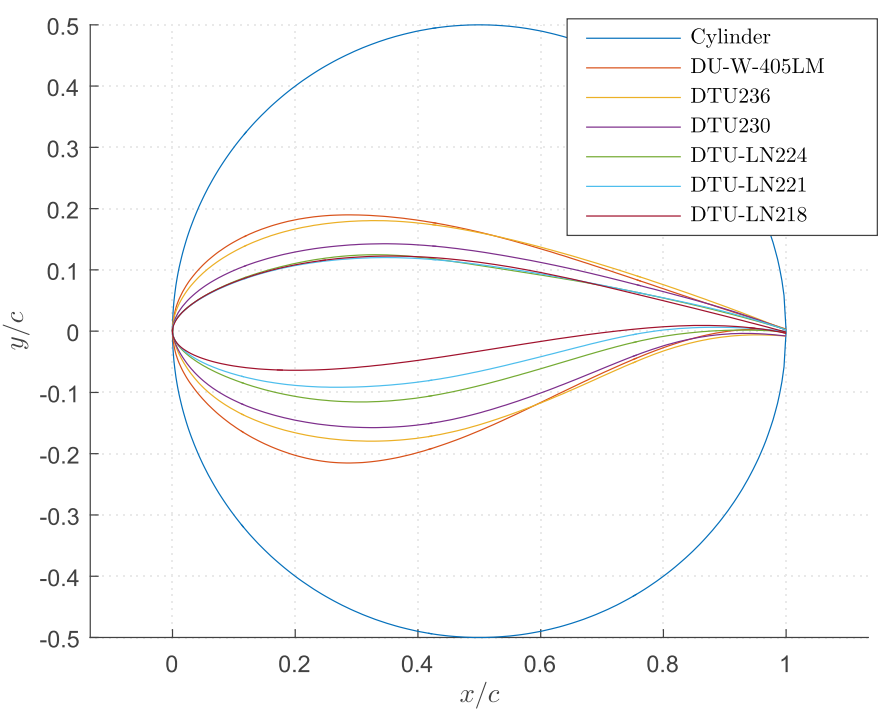

Figure 3. Airfoil profiles used for the blade design consisting of the DTU series, DU-W-405LM, and a cylinder.

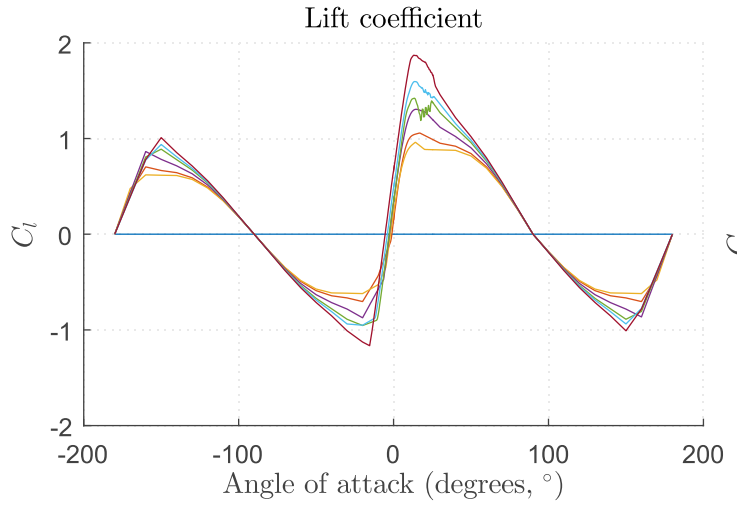

(a)

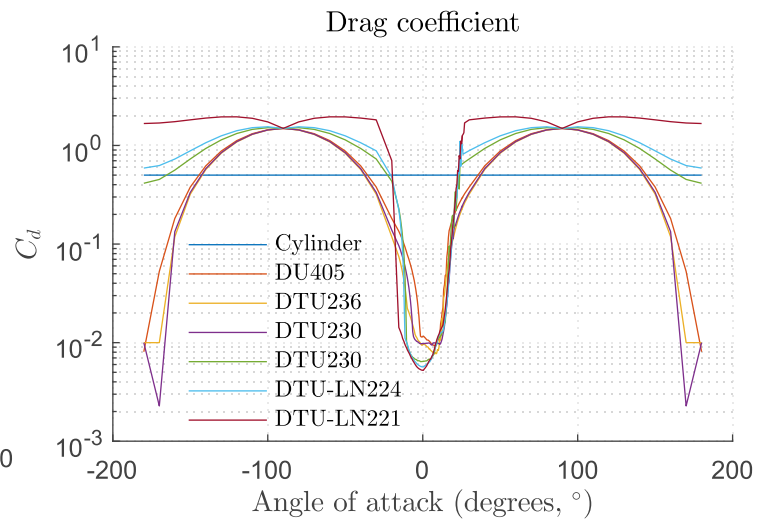

(b)

Figure 4. (a) Airfoil lift; and (b) drag data computed from $Q^{3}$ UIC. A smoothing spline and Viterna extrapolation were applied on the airfoil data.

FLEX5 was selected as the aeroelastic tool to design the outer blade shape of the OffWindChina $5 \mathrm{MW}$ rotor because FLEX5 is computationally inexpensive in comparison with other codes such as FAST [35] and HAWC2 [36]. Although aeroelastic tools such as FLEX5, FAST, and HAWC2 use nearly identical aerodynamic modelling methodologies, the computational cost varies due to the different structural modeling fidelities and programming implementations. For example, FLEX5 uses the modal analysis as a computationally effective way to analyze wind turbine structural dynamics, while HAWC2 uses a finite-element approach involving a higher number of degrees of freedom [37,38]. Despite using nearly identical modelling approaches, FLEX5 was found to be computationally cheaper than FAST [39], which suggests that the programming implementations between the two codes might differ. Using an inexpensive aeroelastic tool allows a higher number of design variables in the blade design, since increasing the number of variables also carries an increase in computational cost in the optimizer. Similarly, PreComp was selected for the structure due to its low computational cost compared to more advanced structural analysis tools such as BECAS [40] and VABS [41].

As noted by Ning [42], a blade design based purely on aerodynamic optimization gives multiple solutions that produce the same AEP, but with different masses. To reduce COE as much as possible, 
both the aerodynamic and structural characteristics of the rotor must be considered and should be optimized simultaneously. Therefore, a simple optimization tool to design the internal structure of large wind-turbine blades was added in the rotor design framework. The simple structural design tool is used solely as means to take into account some aspect of the structural design in the aeroelastic design optimization of the blade's outer shape. The final structural layup of the blade is determined using the detailed structural design procedure presented in Section 3.

The simple structural design tool uses a combination of PreComp to compute blade structural properties, a finite-element code to compute the blade coupled mode shapes, BModes [43], the Euler-Bernoulli beam theory to compute blade deflections and strains [44], and FLEX5 to compute the design load cases (DLCs). There are a total of five DLCs considered, see [45]. The objective is to minimize the blade mass subject to a number of boundary and non-linear inequality constraints based on blade natural frequency, allowable tip deflection, ultimate tensile and compressive strain, and buckling. The design variables are the spar-cap thickness and web layup. The spar-cap thickness distribution is defined by eight CPs, while the web layup is defined by the chord-wise locations of the span-wise endpoints for each web (i.e., four CPs for a two-web layup are performed here). Linear interpolation is performed to obtain values between the CPs. Upper and lower bounds of the spar-caps and webs are used to prevent them from merging into each other and into different sectors of the cross-section, as well as becoming negative. Details regarding the simple structural design tool are available in reference [45].

To reduce the number of variables that work directly on COE, a two-level optimization approach is used. The first and outer level is a surrogate-based optimization code developed by the authors [45,46] to solve Equation (5) in terms of blade chord, twist and relative thickness distributions. The second and inner level is the structural optimization routine described above which is performed for each candidate blade design from the first/outer level. The second and inner level involves the MATLAB optimizer, fmincon [47], which minimizes the blade mass up to at least a local minimum and also satisfies all the constraints. The second and inner level does not work directly with COE, but rather indirectly through the minimum blade mass which it computes. A flow diagram is available in reference [45].

\subsection{Blade Design Results}

The blade design for the OffWindChina $5 \mathrm{MW}$ rotor was performed using seven different values of rotor radius. An increment/decrement of one meter was used relatively to the reference value of $63 \mathrm{~m}$ from the NREL $5 \mathrm{MW}$ rotor: 60, 61, 62, 63, 64, 65 and $66 \mathrm{~m}$. The effect on COE by increasing or decreasing the rotor radius is shown in Figure 5. Evidently, COE decreases when the rotor radius increases. The reduction in COE for the optimized blade design (Optimum) relative to the baseline (Baseline) is nearly the same for each rotor radius, however this trend is not seen for the AEP, maximum flap-wise root-bending moment experienced in the DLCs, and blade mass in Figure 5. Two possible theories might explain the variability in the root-bending moment and blade mass results in Figure 5 . The first is that the variability in the root-bending moment is due to the changes in loading conditions between the different blade designs in the structural optimization routine. The worst-case loads for one design might be one particular DLC, while a different DLC for another. The abrupt change in the worst-case DLC is propagated in the minimum blade mass optimization. The second theory is related to the two-level optimization approach used. The first level is a global optimizer, while the second inner level is a local optimizer and is susceptible to local minima. Contrary to the second inner level, the number of iterations used in the first and outer level is set based on the maximum computing time available to the user and is not determined based on whether or not the results have converged. The variability in the root-bending moment and blade mass might be caused by non-convergent blade designs from the first level, local minima found in the second level, or a combination of the two.

Based on the results shown in Figure 5, a rotor radius of $65 \mathrm{~m}$ was selected. The optimum rotor with the $65 \mathrm{~m}$ radius produces the lowest COE and does not produce a flap-wise root-bending 
moment greater than the baseline design. The blade mass is also lower than the mass of the rotor with radius $=63 \mathrm{~m}, 64 \mathrm{~m}$ and $66 \mathrm{~m}$. Figure 6 depicts the optimized blade design for the $130 \mathrm{~m}$ diameter rotor. Note that the blade span-wise pitch-axis distribution in Figure 6 is defined from the leading-edge and is relative to the chord length. The pitch-axis is computed using $0.5 \mathrm{c}$ at the blade root and $0.375 \mathrm{c}$ at the blade tip, where the values 0.5 and 0.375 were selected based on a CAD model of the NREL 5 MW blade [48]. The change in pitch axis towards the root region is calculated based on the curvature of the chord in that same location using a MATLAB script from [49].

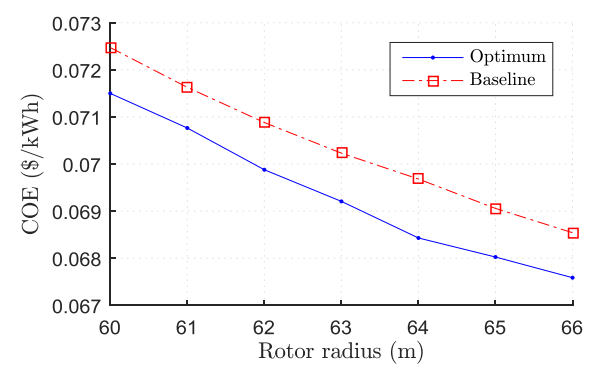

(a)

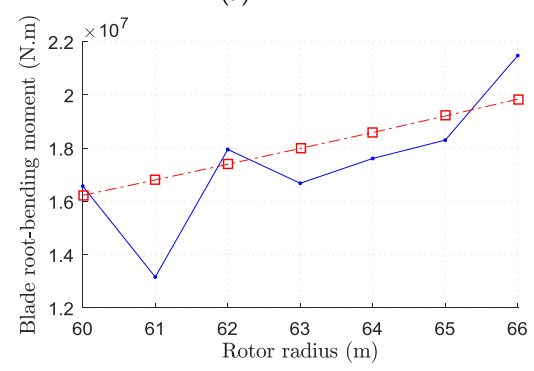

(c)

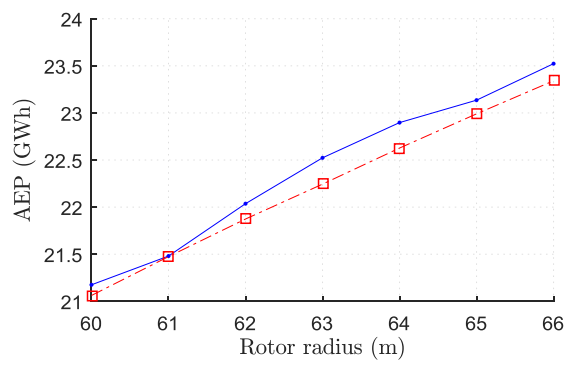

(b)

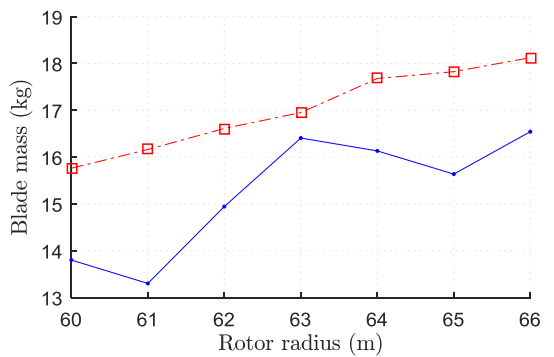

(d)

Figure 5. (a) Cost of energy; (b) annual energy production; (c) flap-wise blade root-bending moment; and (d) blade mass versus rotor radius.

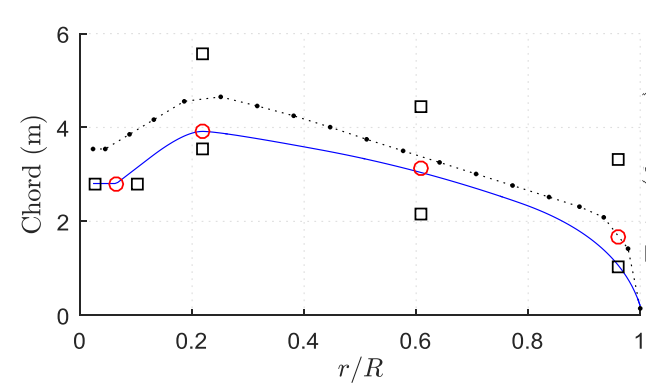

(a)

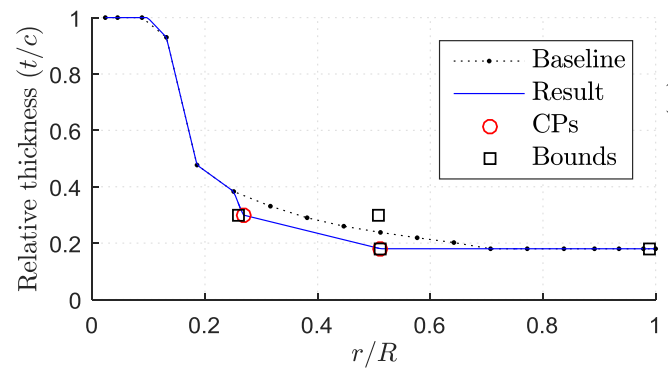

(c)

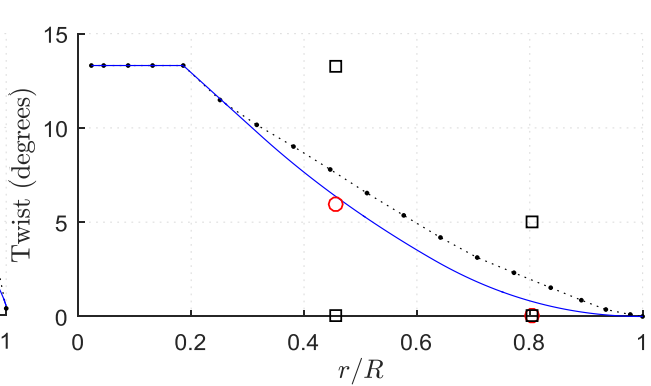

(b)

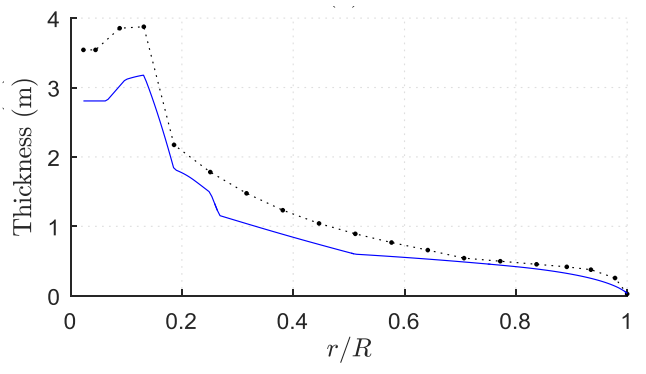

(d)

Figure 6. Cont. 


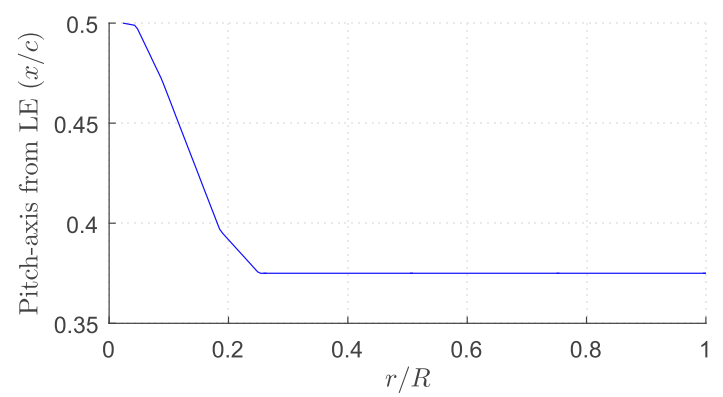

(e)

Figure 6. Final blade design results for the OffWindChina $5 \mathrm{MW}$ rotor with a radius of $65 \mathrm{~m}$. (a) Chord; (b) twist; (c) relative thickness; (d) thickness; and (e) pitch-axis from LE. The pitch axis, $x$, is defined from the leading edge (LE) and is relative to the chord length, $c$.

Figure 7 depicts the aeroelastic performance of OffWindChina $5 \mathrm{MW}$ against the reference (or baseline) for a wind sweep between 4 and $24 \mathrm{~m} / \mathrm{s}$. The NREL $5 \mathrm{MW}$ performance is included for comparison as well. Figure 7 shows that the optimized design produces more electrical power (top-right) and less thrust (bottom-right) than the baseline design.

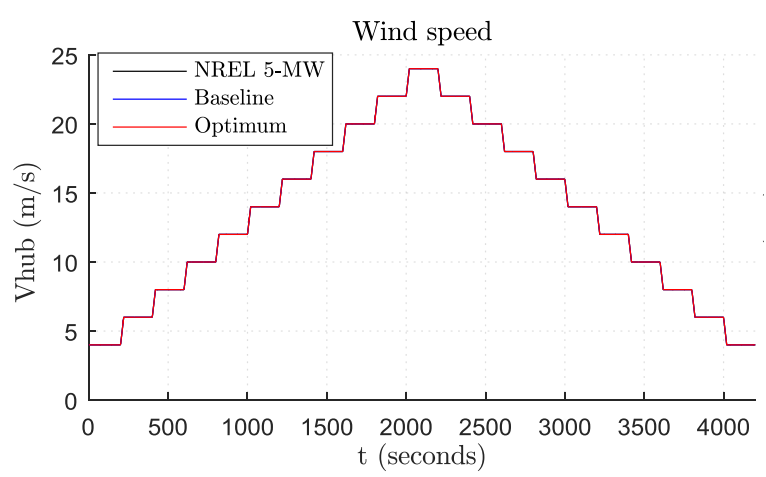

(a)

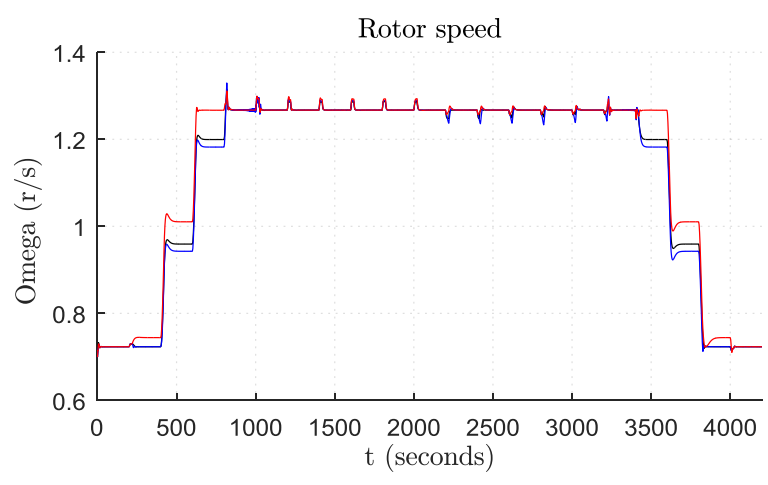

(c)

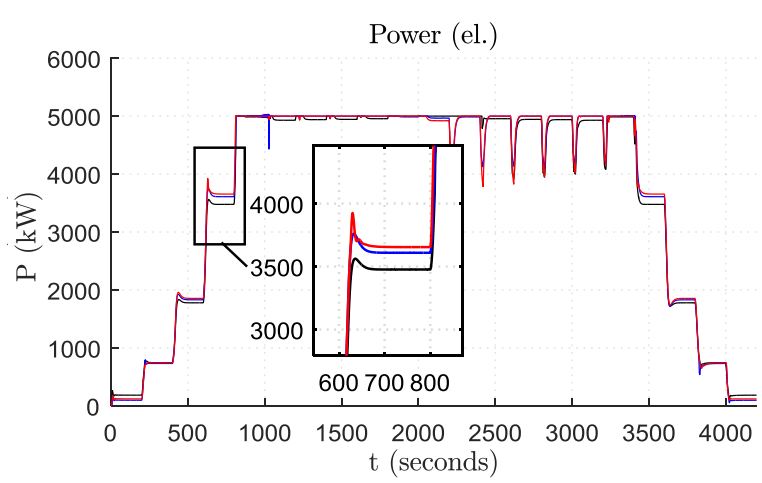

(b)

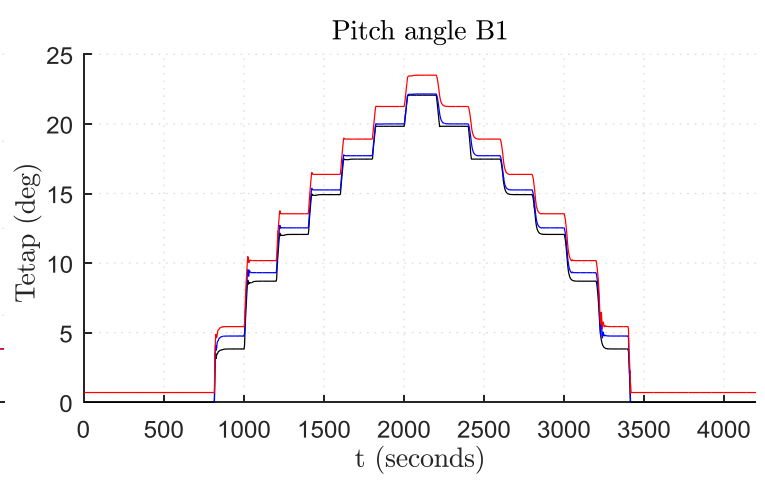

(d)

Figure 7. Cont. 


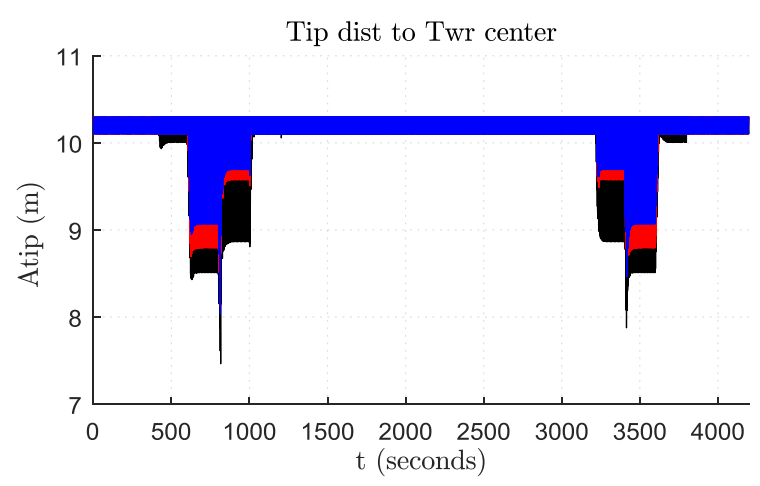

(e)

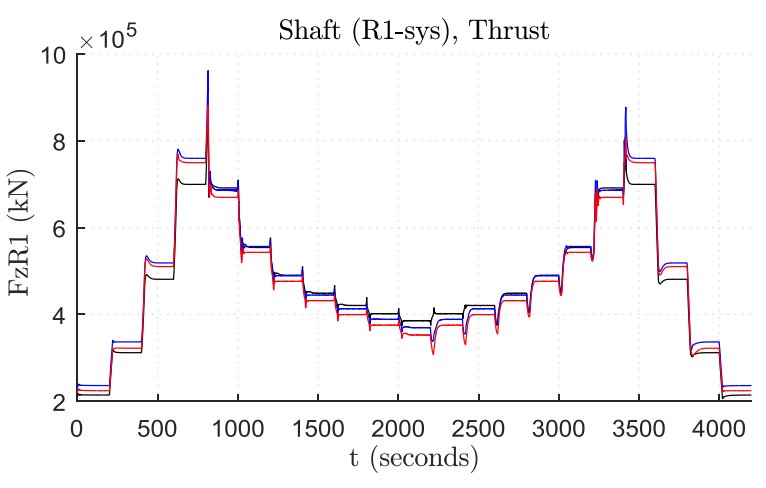

(f)

Figure 7. OffWindChina $5 \mathrm{MW}$ performance (Optimum) compared to the baseline and the NREL $5 \mathrm{MW}$ for an increasing and a decreasing wind speed simulation. (a) Wind speed at hub height; (b) electrical power; (c) rotor speed; (d) pitch angle; (e) tip distance to tower center; and (f) shaft thrust.

However, the horizontal distance between the blade tip pointing closest towards the ground and the tower center (tip distance to tower center) is smaller for the optimized design than the baseline between 10 and $12 \mathrm{~m} / \mathrm{s}$ wind speeds (600-1000 and 3200-3600 s). Given that the tower radius is approximately $2.6 \mathrm{~m}$ from [30], the blade tips are at least $5.4 \mathrm{~m}$ away from tower strike. Nevertheless, a more detailed structural design is presented in the next section, which will address the structural feasibility of the blade with more rigors.

\section{Structural Design}

Based on the aerodynamic blade shape obtained in Section 2, the present section focuses on the detailed blade structural design. The section consists of the following four subsections: (1) Design Variables, (2) Problem Formulation, (3) Numerical Tools, and (4) Blade Design Results.

\subsection{Design Variables}

A typical structural configuration of a blade cross-section is adopted in the present structural design, see Figure 8. The first ply or skin (marked as SK in Figure 8) of the blade is made of gel-coat, whose main function is to keep a smooth blade surface. When erosion occurs, the gel-coat skin can be repaired to keep the blade continually smooth. Due to the lack of ultimate strength data and the negligible effect that the gel-goat has on the overall blade strength, the strength of the gel-coat is not examined. Tri-axial (TA) plies are used as skin reinforcements and are marked as SKR in Figure 8. In this paper, the SKR contains two TA plies. Surrounding the inner side of the blade shell, unidirectional (UD) glass, UD carbon, TA and foam are laid out according to local requirements. The combination of caps and shear webs carries the main structural loads. As the cap (shown as CAP in Figure 8) resists most of the blade bending moments, UD carbon plies are heavily layered there.

To design a blade as light as possible while maintaining structural feasibility requirements, the optimization of composite layers is of paramount importance. The span-wise distribution of the number of UD carbon layers is defined by three variables: N1, N2 and Lcap. The rotor radius is $65 \mathrm{~m}$ with a hub radius of $1.5 \mathrm{~m}$. Two CPs located at the span-wise locations of $r=14 \mathrm{~m}$ (with the maximum chord) and $r=42.5 \mathrm{~m}$ (around $0.6 \mathrm{R}$ ), where $r$ is the radial distance to the hub center. The two span-wise locations are denoted as $R 1$ and $R 2$, respectively. The number of UD carbon plies in the span-wise range from $r=R 1-L$ cap $/ 3$ to $r=R 1+2 L$ cap $/ 3$ is constant and is labeled as N1 in Figure 9. The number of UD carbon at $R 2$ is $N 2$. Linear interpolation is performed to obtain values between $R 1$ and $R 2$. Moreover, the arc length of the cap is selected as an optimization variable and is denoted as Wcap. The design variables are listed in Table 1. 


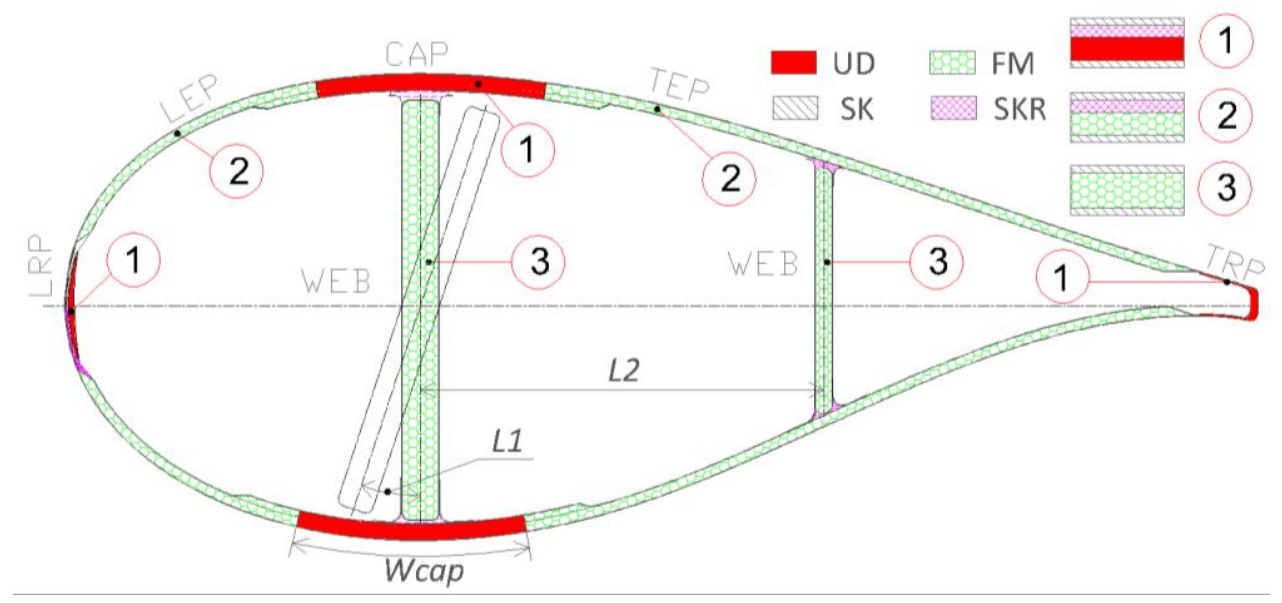

Figure 8. Typical structural configuration of a blade cross-section.

The web, also called shear web, resists the flap-wise shearing force. The shear web is designed to increase the rigidity of the blade and prevent local instability. As shown in Figure 8, the shear web consists of bi-directional (BD) laminates in the outer part of the web and foam in the inner part of the web. The foam is marked as FM in Figure 8. The connection points between the leading-edge web and the cap equally split the arc length Wcap. Therefore, a rotation of the webs also leads to a rotation of the cap. As discussed in Section 1, the spar location should be twisted along the blade span. The twisting causes the web to become a curved surface rather than a plane. In the current article, the angle between the local web section and the tip chord decreases linearly from the root to the tip. At the blade root, the angle of the leading-edge shear web is $L 1$ with its origin aligned with the pitch axis of the blade. $L 1=0$ is normal to the tip chord and in the down-wind direction, and $L 1>0$ is in the clockwise rotation of the web. The angle of the shear web at the blade tip is set to be zero. The angle of the trailing-edge web is equal to the angle of the leading-edge web. The perpendicular distance between the two shear webs, $L 2$, is chosen as an optimization variable, which is also shown in Figure 8.

The leading- and trailing-edge reinforcement panels are abbreviated as LRP and TRP, respectively. They are designed to resist the lead-lag (edgewise) bending moments. In [20,50], topology optimizations of blade structure showed that the presence of trailing-edge reinforcement leads to a more structurally efficient blade. UD glass plies are laid at LRP and TRP to withstand the bending moments. In the span-wise range from $r=R 1-L$ cap $/ 3$ to $r=R 1+L c a p / 3$, the number of UD glass plies at LRP and TRP are N3 and N4, respectively. Linear interpolation is performed to obtain values in the whole span-wise range.

The leading- and trailing-edge panels are abbreviated as LEP and TEP, respectively. The sandwich-like structure with foam being the core is used here to keep the aerodynamic shape and provide buckling resistance. The foam thickness is chosen as another optimization variable and set to a multiple of $5 \mathrm{~mm}$. In the range from $r=R 1-L c a p / 3$ to $r=R 1+2 L c a p / 3$, the foam thickness at LEP and TEP are set to be $T 1$ and T2, respectively. The thickness at TEP just after $r=R 1+2 L$ cap $/ 3$ is still $T 2$, as shown in Figure 9, has no conflict with the above definition because the thickness is interpolated to a multiple of five. The same rule is used for LEP. The number of plies shown in Figure 9 is set arbitrarily just to demonstrate the optimization variable. However, $T 2$ is set to be twice of $T 1$ in the optimization so that only one optimization variable $T 2$ is added in Table 1. 


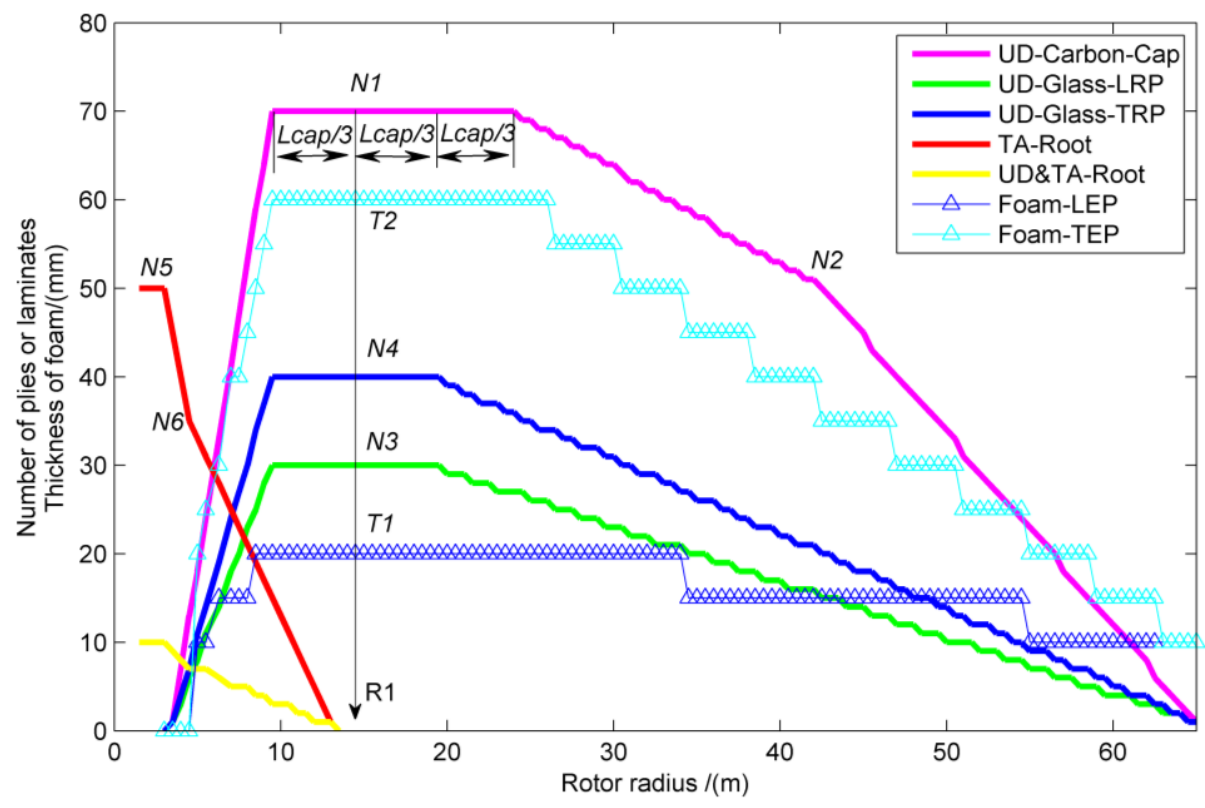

Figure 9. Design variables NC1, NC1, Lcap, NR1, Nr2.

The blade root experiences large bending and torsional moments, and additional reinforcement laminates are needed here. Normally, these laminates start from the blade root and extend to locations near $R 1$ (the ending point is chosen as $R 1-0.5 \mathrm{~m}$ here). Commonly, the blade root contains UD, BD and TA plies. The BD plies provide resistance to the torsional moments. Since the TA plies work similarly as the combination of UD and BD plies, the BD plies are not used in order to facilitate the design and manufacturing process. First, many layers of the UD\&TA laminates (consisting one UD ply and one TA ply) are laid in the outer part of the shell. The number of UD\&TA laminates, shown by the solid yellow line in Figure 9, should be optimized. Then, the plies extended from the outboard regions (LRP, LEP, CAP, TEP, TRP) are laid following the trends as shown in Figure 9. Afterwards, many UD\&TA laminates are laid again with the same number as that of the outermost UD\&TA laminates. Finally, many TA plies are laid in the inner part of the shell, which is represented by the solid red line in Figure 9. The number of TA plies is set to be N5 at the cylindrical blade root and changes to N6 at $r=4.5 \mathrm{~m}$. The number of TA plies is set to be five times that of UD\&TA laminates in this paper.

Table 1. Description of design variables.

\begin{tabular}{ccc}
\hline Variable & Description & Boundary \\
\hline N1 & Number of UD carbon plies at cap $(r=R 1-L$ cap $/ 3$ to $r=R 1+2 L c a p / 3)$ & $100-140$ \\
N2 & Number of UD carbon plies at cap $(r=R 2 \mathrm{~m})$ & $95-135$ \\
Lcap & Span-wise length with a same number of UD carbon plies & $15-30 \mathrm{~m}$ \\
Wcap & Arc length of the cap & $0.4-0.9 \mathrm{~m}$ \\
L1 & Installation angle of shear webs & $-10-15$ degree \\
$L 2$ & Perpendicular distance of the two shear webs & $0.6-1.0 \mathrm{~m}$ \\
N3 & Number of UD glass plies at LRP $(r=R 1-L$ cap $/ 3$ to $r=R 1+L$ cap $/ 3)$ & $30-50$ \\
$N 4$ & Number of UD glass plies at TRP $(r=R 1-L$ cap $/ 3$ to $r=R 1+L c a p / 3)$ & $20-40$ \\
N5 & Number of TA plies of root reinforcement $(r=1.5 \mathrm{~m}$ to $r=3 \mathrm{~m})$ & $20-40$ \\
$N 6$ & Number of TA plies of root reinforcement $(r=4.5 \mathrm{~m})$ & $5-20$ \\
T2 & Total thickness of foam at TEP $(r=R 1-L$ cap $/ 3$ to $r=R 1+2 L$ cap $/ 3)$ & $20-100 \mathrm{~mm}$ \\
\hline
\end{tabular}

\subsection{Problem Formulation}

For the blade structural design, the design objective is to minimize the blade mass. The constraints are on material strength, blade natural frequency, and blade rigidity. The strength of the blade is constrained such that the composite materials must not fail when the blade endures the extreme 
loads. The failure criterion of Tsai-Wu was utilized which requires the failure factor, $f_{t s w}$, to be smaller than one:

$$
f_{t s w}=\frac{\sigma_{1}^{2}}{X_{t} X_{c}}+\frac{\sigma_{2}^{2}}{Y_{t} Y_{c}}+\frac{\tau_{12}^{2}}{S^{2}}+\left(\frac{1}{X_{t}}-\frac{1}{X_{c}}\right) \sigma_{1}+\left(\frac{1}{Y_{t}}-\frac{1}{Y_{c}}\right) \sigma_{2}-\frac{\sigma_{1} \sigma_{2}}{\sqrt{X_{t} X_{c} Y_{t} Y_{c}}}<1
$$

where $\sigma_{1}, \sigma_{2}$ and $\tau_{12}$ are the three in-plane stress components in the local orthotropic ply axis, and $X_{t}$, $X_{c}, Y_{t}$ and $Y_{c}$ are the corresponding material strengths, which are directly taken from the uniaxial load experiments. The skin of the blade is used to keep the smoothness of the blade surface and its strength is not examined. The foam is used to keep the blade shape and the force is mainly resisted by the other laminates. Therefore, the foam is not examined by the Tsai-Wu failure criterion and also due to the lack of ultimate strength data. Concerning the rigidity, the distance between the blade tip and the tower must not reach $70 \%$ of the distance between the hub and the tower. Therefore, the maximum flap-wise tip displacement was constrained to be below $7.1 \mathrm{~m}$ in order to ensure an adequate tower clearance. Moreover, the natural frequency of the blade should be constrained to avoid resonance.

To yield a blade capable of withstanding the extreme conditions during 20 years lifespan, the design loads should cover all the extreme conditions. To shorten the optimization time, five DLCs were used by FLEX5 in Section 2 to obtain the design loads. In this section, the commercial software GH Bladed was used instead to calculate the extreme loads under more DLCs. The span-wise distribution of ultimate bending moments was extracted from all GH Bladed calculations. The DLCs considered are DLC1.1, DLC1.3-DLC1.5, DLC2.3, DLC3.2, DLC3.3, DLC4.1, DLC4.2, DLC5.1, DLC6.1, DLC6.3, DLC7.1 and DLC8.1. Detailed settings about the DLCs follow the standard IEC 61400-1 [28]. A positive flap-wise bending moment causes a compression on the suction side and a negative edgewise bending moment causes a compression at the trailing-edge. Then, the normal and tangential (with respect to the local chord) moments were transformed into $\mathrm{Mx}$ (parallel to the chord line at tip) and My (perpendicular to the chord line at tip). The span-wise distribution of Mx and My are shown in Figure 10.

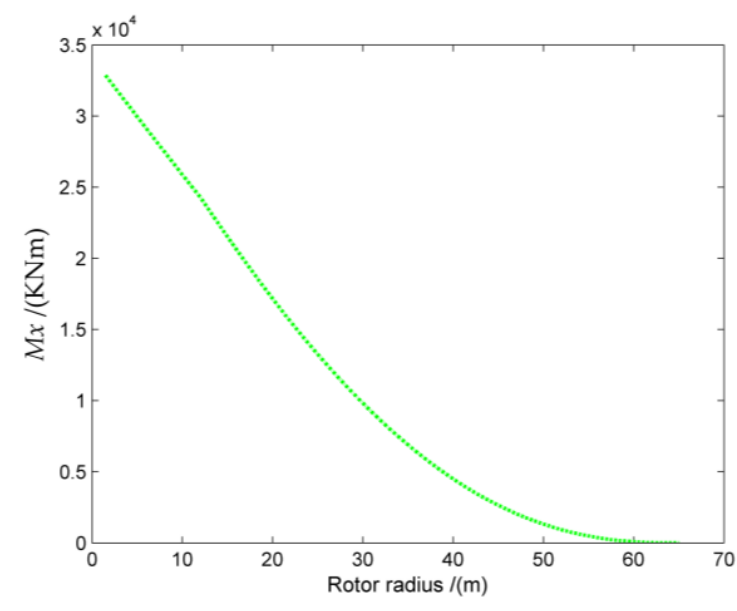

(a)

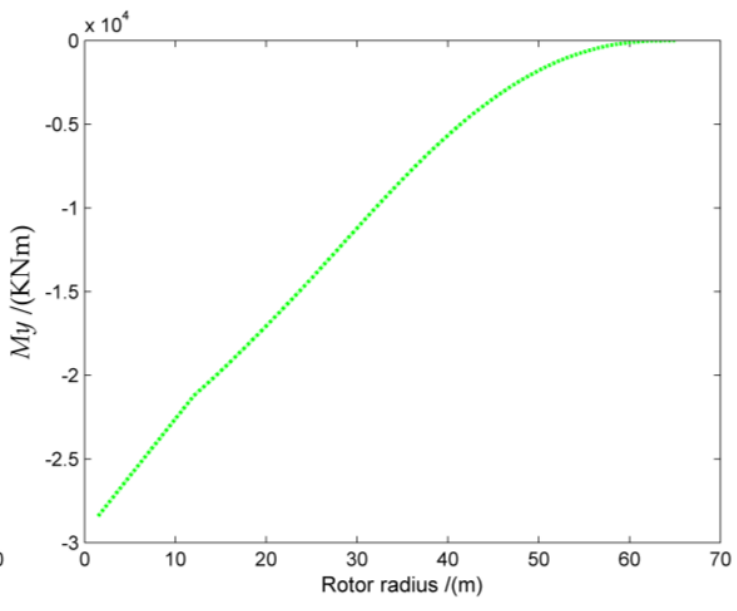

(b)

Figure 10. Span-wise distribution of: (a) $M x$; and (b) $M y$.

\subsection{Numerical Tools}

In the present design, the finite element model in the ANSYS commercial package with Shell181 (4-node) elements is used, in which the material properties, thickness and fiber align angle of each layer are modeled. To construct the blade shape, 25 blade sections are used with sections densely placed near the blade tip and the root transition zone. Airfoils are modeled with a blunt trailing-edge. The element 
size is set to be no bigger than $0.1 \mathrm{~m} \mathrm{[51]} \mathrm{in} \mathrm{order} \mathrm{to} \mathrm{adequately} \mathrm{capture} \mathrm{the} \mathrm{structural} \mathrm{performance.}$ The mesh near the tip is dense to avoid a large aspect ratio, which can cause numerical difficulties to FEM calculations. The degree-of-freedom is fixed at the nodes of the root connection. The tip deflection and the stress and strain on every node can be extracted and used in the optimization process.

MATLAB and ANSYS are combined together to automatically model the blade of composite materials and evaluate the objective and constraint functions. The blade structural optimization process, depicted in Figure 11, was performed utilizing a particle swarm optimization (PSO) algorithm [52]. The particle swarm needs to be randomly initiated within the design boundaries shown in Table 1 . The variables from the PSO population are saved in a specific output format through MATLAB. Based on the blade shape from Section 2 and the PSO variables, the finite element (FE) model of the blade was constructed using the ANSYS Parametric Design Language (APDL) macro files. Then, the design loads were interpolated onto the FE mesh. Afterwards, the FE models were solved using static and linear analyses. The results are outputted to an external file that MATLAB reads to examine the objective and constraint functions. In the PSO algorithm, the velocity of each particle is adjusted during the optimization process:

$$
V_{i+1}=w_{i} V_{i}+c_{\text {rand }, 1} c_{1, i} V_{\text {pbest }, i}+c_{\text {rand }, 2} c_{1, i} V_{\text {gbest }, i}
$$

where $V_{i+1}$ is the particle velocity of the next generation, $V_{i}$ is the particle velocity of the current generation, $w_{i}$ is the inertia factor representing the inertial effects from current generation, $V_{p b e s t, i}$ is the single particle's best known velocity from the generations until $i, V_{g b e s t, i}$ is the swarm's best known velocity from the generations until $i, c_{1, i}$ and $c_{2, i}$ are the learning factors that control the learning process of the particles, and $c_{r a n d, 1}$ and $c_{r a n d, 2}$ are two random numbers between one and zero. The PSO algorithm used here employs adaptive weighting and learning factors that are different to those in the standard PSO algorithm [52]:

$$
\left\{\begin{array}{l}
w_{i}=w_{\max }-\left(w_{\max }-w_{\min }\right) \cdot \tanh \left((i / \text { Max Iter })^{2}\right) \\
c_{1, i}=c_{1, \max }-\left(c_{1, \max }-c_{1, \min }\right) \cdot \sqrt{\tanh (i / \text { MaxIter })} \\
c_{2, i}=c_{2, \min }+\left(c_{2, \max }-c_{2, \min }\right) \cdot \sqrt{\tanh (i / \text { MaxIter })}
\end{array}\right.
$$

where the upper and lower bounds of the weighting factor are controlled by $w_{\max }=0.8$ and $w_{\min }=0.05$, and the bounds of the learning factors are controlled by $c_{1, \max }=1.2, c_{1, \min }=0.3$, $c_{2, \max }=1.2$ and $c_{2, \min }=0.3$.

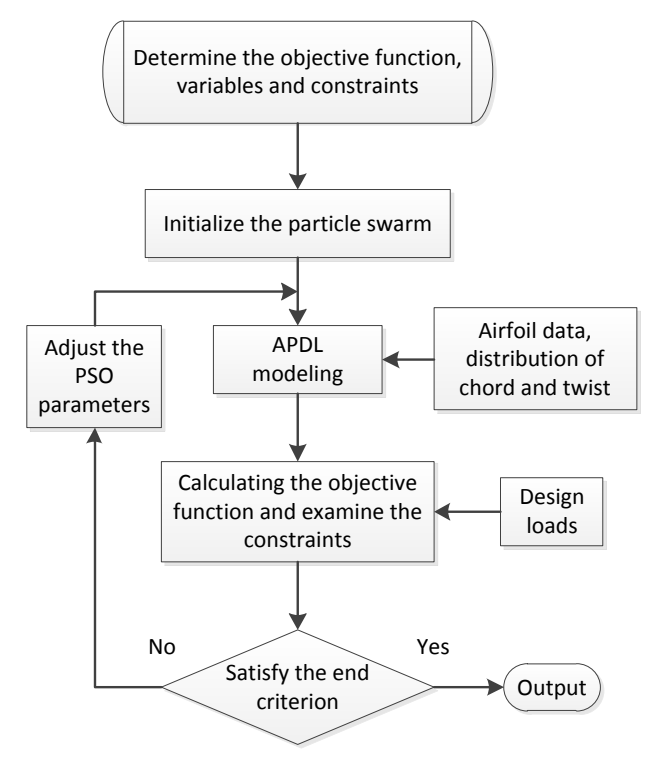

Figure 11. Flow chart of the structural design procedure. 


\subsection{Blade Design Results}

\subsubsection{Baseline Blade Description}

A baseline blade is constructed to compare with the following optimization results. The design variables for the baseline blade model are listed in Table 2. The distribution of the materials along the blade span in the initial blade design is depicted in Figure 12. Beside the design variables listed in Table 2, other less important distributions are shown in Figure 12, such as the number of UD-glass plies of LEP and TEP, and the thickness of the foam at the leading- (web1) and trailing-edge webs (web2). The weight of the constructed FE blade model is $17,787 \mathrm{~kg}$, which is close to the $17,700 \mathrm{~kg}$ of the $61.5 \mathrm{~m} 5 \mathrm{MW}$ reference wind turbine blade [51]. The maximum out-of-plane tip displacement is $7.0876 \mathrm{~m}$, which nearly reaches the maximum allowable tip deflection of $7.1 \mathrm{~m}$.

Table 2. Description of design variables.

\begin{tabular}{cccccccccccc}
\hline Variable & N1 & N2 & Lcap & Wcap & L1 & L2 & N3 & N4 & N5 & N6 & T2 \\
\hline Initial & 135 & 125 & $27.00 \mathrm{~m}$ & $0.6000 \mathrm{~m}$ & 8.50 degree & $0.8000 \mathrm{~m}$ & 35 & 30 & 30 & 10 & $60 \mathrm{~mm}$ \\
Optimized & 100 & 126 & $23.00 \mathrm{~m}$ & $0.7885 \mathrm{~m}$ & 9.99 degree & $1.0000 \mathrm{~m}$ & 50 & 27 & 20 & 8 & $20 \mathrm{~mm}$ \\
\hline
\end{tabular}

The Tsai-Wu failure factors, $f_{t s w}$, are smaller than one. A modal analysis was performed to determine the natural frequency of the initial blade with a fixed root. The obtained natural frequencies for the first six modes are compared with those of the reference blade [51] in Table 3. The natural frequencies between the baseline (or initial) and reference blades are close to each other, which shows the similarities of the blade properties.

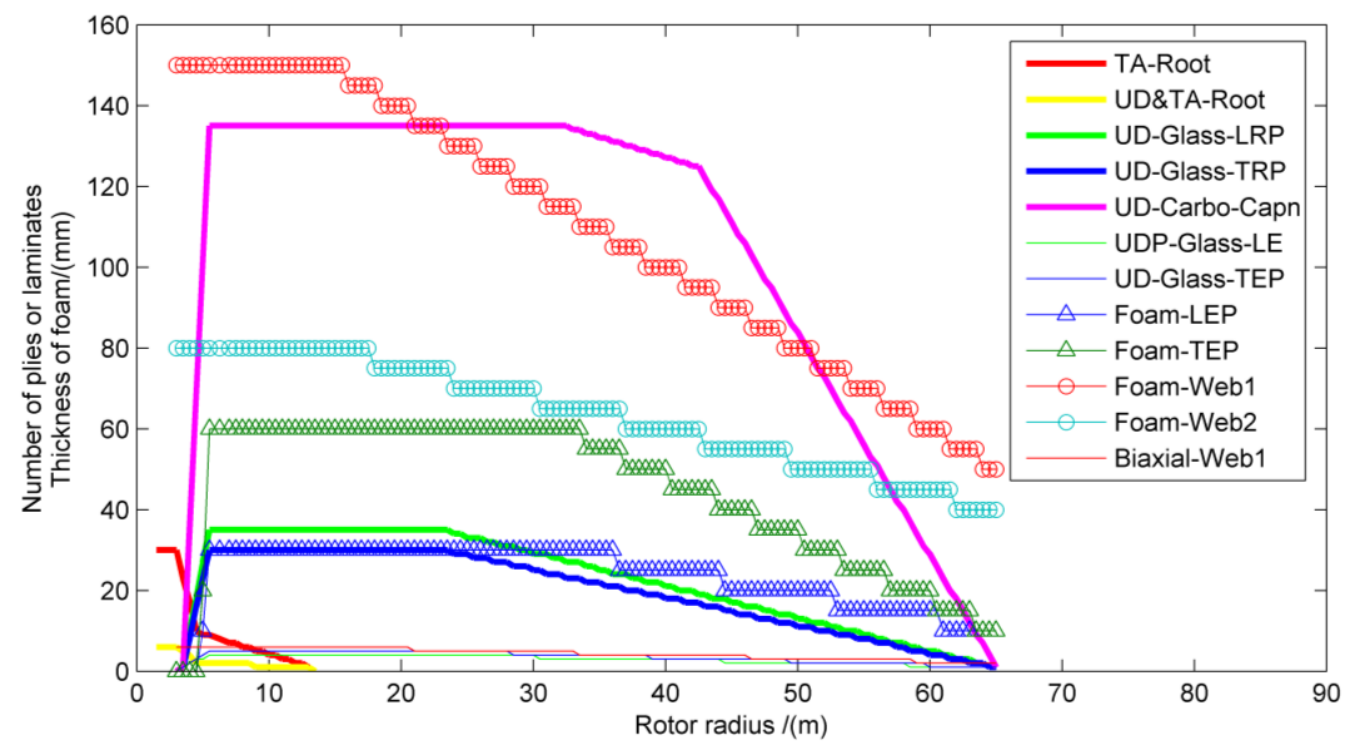

Figure 12. Layup of composite materials of the initial blade.

\subsubsection{Optimization Results}

As shown in Figure 13, the optimization process converges to a minimum mass of 15,684 $\mathrm{kg}$ before reaching the maximum iteration number. The mass reduction relative to the NREL 5 MW blade is 2016 $\mathrm{kg}$, or $11.39 \%$. The optimized values of the design variables are listed in Table 2 . The distribution of the plies and laminates are compared with those of the initial blade in Figure 14. The number of UD carbon plies of cap, in the span-wise range from $r=R 1-L$ cap $/ 3$ to $r=R 1+2 L$ cap $/ 3$, has decreased from 135 to 100. However, the number of UD carbon plies from $r=R 1+2 L$ cap $/ 3$ to $r=R 2$ is increasing. The arc length of the cap has increased from 0.6000 to $0.7885 \mathrm{~m}$, which means that the cap is getting 
wider. The angle of the shear web at the blade root is $9.99 \mathrm{deg}$, which also means that the cap is rotated. The rotation has led to the upper spar cap (suction side) to move towards the trailing-edge, as shown in Figure 15, which is consistent with the findings from the topology optimization from [50]. The trailing-edge web moves towards the trailing-edge and reaches the upper limit. The number of UD glass plies at LRP has increased up to the upper boundary and that at TRP has slightly decreased. The number of root reinforcement laminates at $r=3 \mathrm{~m}$ and the thickness of the panel foam at LEP and LTP reach their lower boundaries.

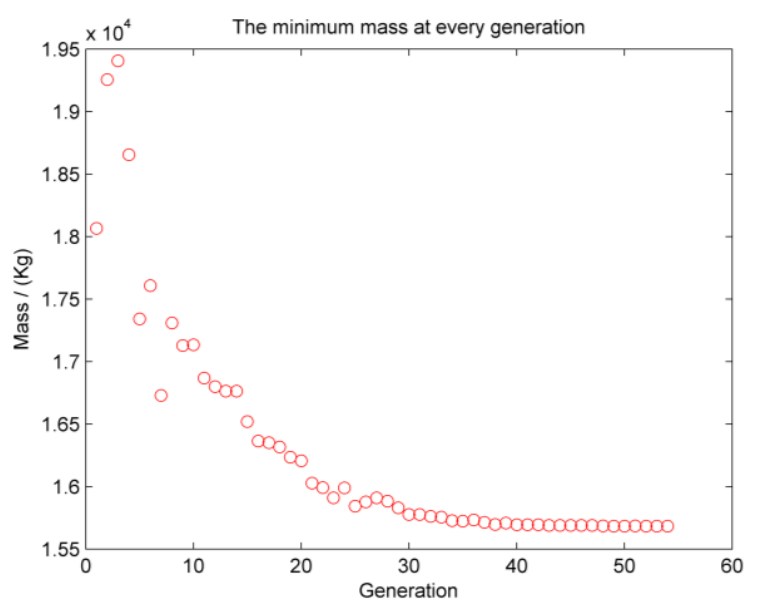

Figure 13. Optimization process converging to a minimum blade mass of $15,684 \mathrm{~kg}$.

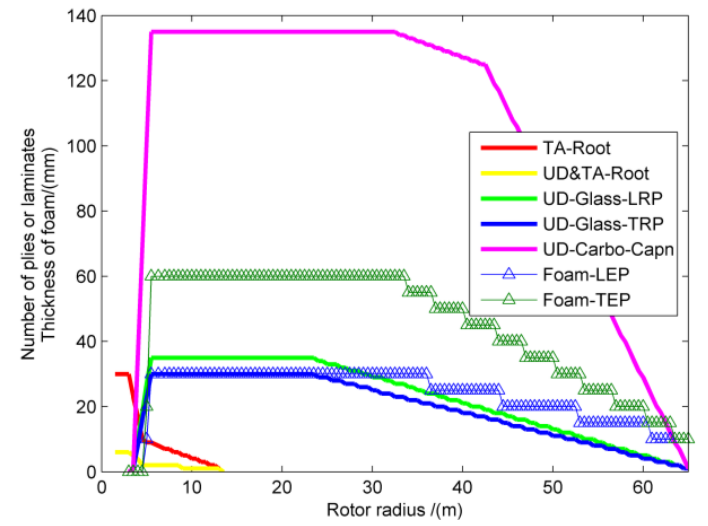

(a)

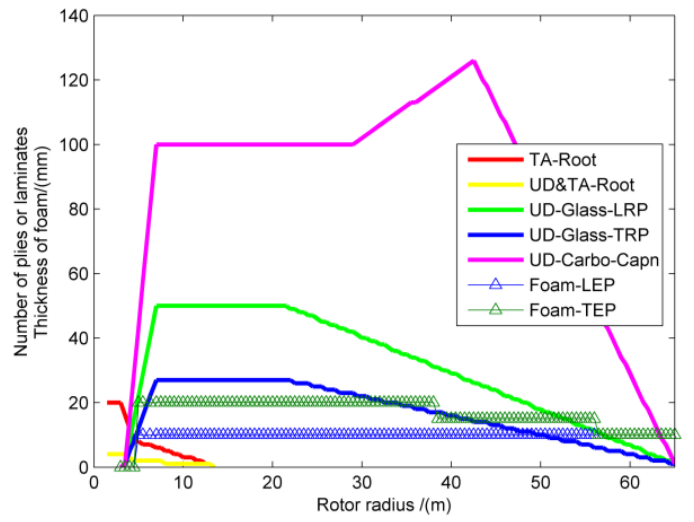

(b)

Figure 14. Comparison of the material layups between the (a) initial; and (b) optimized blades.

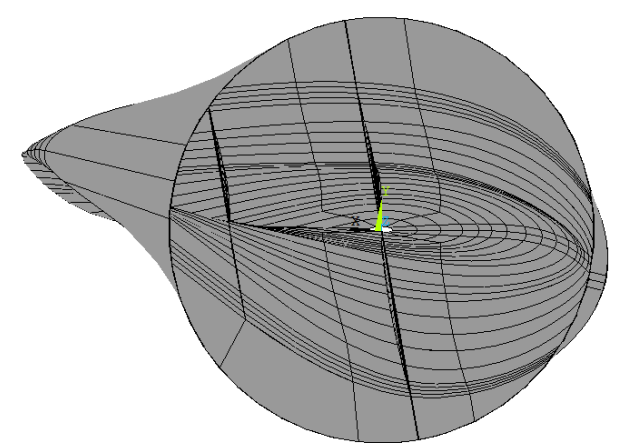

Figure 15. Rotation angle of the webs. 
Table 3. Modal frequencies of the initial and optimized blades.

\begin{tabular}{cccc}
\hline Mode & Reference [51] & Initial & Optimized \\
\hline 1 & $0.87 \mathrm{~Hz}$, 1st flapwise & $0.82 \mathrm{~Hz}$, 1st edgewise & $0.79 \mathrm{~Hz}$, 1st edgewise \\
2 & $1.06 \mathrm{~Hz}$, 1st edgewise & $1.02 \mathrm{~Hz}$, 1st flapwise & $0.98 \mathrm{~Hz}, 1$ st flapwise \\
3 & $2.68 \mathrm{~Hz}$, 2nd flapwise & $3.03 \mathrm{~Hz}$, 2nd flapwise & $3.13 \mathrm{~Hz}$, 2nd flapwise \\
4 & $3.91 \mathrm{~Hz}$, 2nd edgewise & $3.61 \mathrm{~Hz}$, 2nd edgewise & $3.77 \mathrm{~Hz}$, 2nd edgewise \\
5 & $5.57 \mathrm{~Hz}$, 2nd flapwise & $5.81 \mathrm{~Hz}$, 1st torsion & $5.76 \mathrm{~Hz}$, 1st torsion \\
6 & $6.45 \mathrm{~Hz}$, 1st torsion & $6.16 \mathrm{~Hz}$, 3rd flapwise & $6.40 \mathrm{~Hz}$, 3rd flapwise \\
\hline
\end{tabular}

The optimized blade satisfies all the design requirements. Table 3 presents the calculated natural frequencies in comparison with those of the NREL 5 MW blade and initial blades. The cut-in and rated rotor speeds are designed to be $6.9 \mathrm{rpm}$ and $12.1 \mathrm{rpm}$, respectively. Under the normal working state, the highest passing frequencies of one blade and three blades are $0.2017 \mathrm{~Hz}$ and $0.6050 \mathrm{~Hz}$, respectively. The lowest natural frequency of the optimized blade, $0.7875 \mathrm{~Hz}$ is larger than the blade passing frequencies, which avoids resonance. According to Table 3, the flap-wise and edgewise vibrations are the main vibrations of the blade. The vibration mode shapes of the blade are demonstrated in Figure 16. It is worth noting that the rotational vibrations do not appear in the first four modes, which shows a relative strong resistance to rotation. It is found that the rotational vibrations of the NREL 5 MW blade appear mainly in the sixth mode. Since the new blade is optimized without a limitation on the maximum rotational angle, the torsional stiffness is relatively smaller.

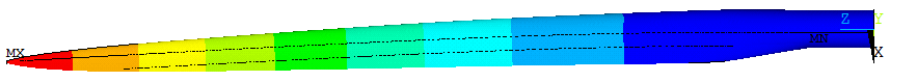

(a)

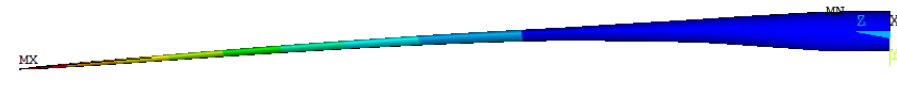

(b)

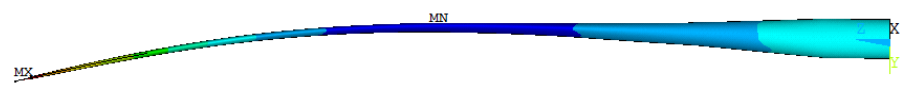

(c)

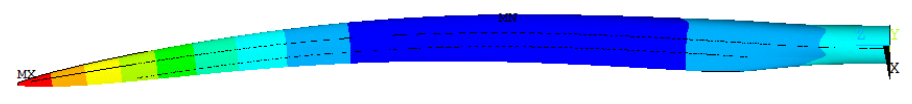

(d)

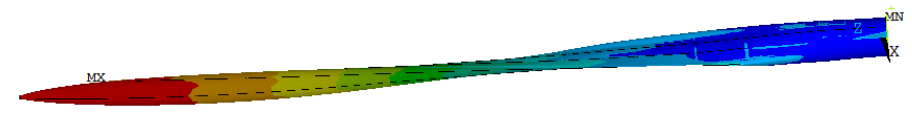

(e)

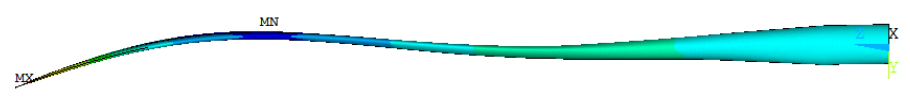

(f)

Figure 16. Mode shape of the optimized blade. (a) First mode shape; (b) second mode shape; (c) third mode shape; (d) fourth mode shape; (e) fifth mode shape; and (f) sixth mode shape.

The Tsai-Wu failure factors are below one. Since the first ply or skin is the gel-coat and was not examined, the maximum Tsai-Wu failure factors for the 2nd to 7th plies of the blade shell are listed in Table 4. The failure factors near the first element (at the very end of the web near the blade root) of the trailing-edge web are influenced by the stress concentration. When excluding the elements with stress 
concentrations, the maximum Tsai-Wu failure factors for the 1st and 2nd BD plies of the two webs are 0.8148 and 0.8137 , respectively. The failure factors for the optimized blade are listed in Table 4.

Table 4. Maximum Tsai-Wu failure factors of plies.

\begin{tabular}{ccccccccc}
\hline Ply No. & 2nd & 3rd & 4th & 5th & 6th & 7th & 1st (Web) & 2nd (Web) \\
\hline Initial & 0.52219 & 0.4904 & 0.5631 & 0.5192 & 0.5338 & 0.4530 & 0.9302 & 0.9118 \\
Optimized & 0.6624 & 0.6369 & 0.8927 & 0.6074 & 0.8433 & 0.5726 & 0.8148 & 0.8137 \\
\hline
\end{tabular}

The maximum out-of-plane tip displacement is $7.0997 \mathrm{~m}$ which is close to the constrained condition of $7.10 \mathrm{~m}$. With the blade rigidity approaching the design limit, meanwhile satisfying other design constraints, a maximum mass decrease of $2016 \mathrm{~kg}$ was obtained. Comparing the Tsai-Wu failure factors, it was found that the maximum tip displacement or rigidity of the blade is the main constraint for the further reduction of the blade mass. This implies that the mass of the blade can be greatly reduced if a larger tip-tower clearance is allowed. Since offshore wind turbines are approaching towards the $10 \mathrm{MW}$-scale and higher, the blade mass will increase dramatically. The increase in blade mass for larger rotors will be one of the main obstacles for further reducing the cost of wind energy. Pre-bent blades and other novel designs should be investigated and employed to increase the tip-tower clearance.

\section{Conclusions}

The current article describes the conceptual design of a $5 \mathrm{MW}$ wind turbine rotor with wind conditions at an offshore site in southeastern China (OffWindChina). The OffWindChina 5 MW design work was divided into aeroelastic and structural design phases. The aeroelastic part determines the optimal outer shape of the blade, while the structural part determines the internal laminate layup. Results demonstrate that the new rotor design yields a high energy output while maintaining structural feasibility with respect to international standards. The blade mass is reduced by $11.39 \%$ with respect to the NREL 5 MW blade. The new blade satisfies all the design requirements, with the blade rigidity approaching the design limit. It is found that the spar cap on the suction side of the blade tends to move towards the trailing-edge. Further optimizations should be conducted including blade pre-bend, fatigue, and buckling.

Acknowledgments: This research was supported by the Danish Council for Strategic Research under the project name OffWindChina (Sagsnr. 0603-00506B).

Author Contributions: Wen Zhong Shen and Jin Chen conceived and designed the project; Zhenye Sun and Matias Sessarego performed the computations and analyzed the results; Zhenye Sun, Matias Sessarego, Wen Zhong Shen and Jin Chen wrote the paper.

Conflicts of Interest: The authors declare no conflict of interest.

\section{References}

1. Global Wind Energy Council. Global Wind Energy Outlook 2016; Global Wind Energy Council: Brussels, Belgium, 2016.

2. Global Wind Energy Council. Global Wind Report: Annual Market Update; Global Wind Energy Council: Brussels, Belgium, 2015.

3. China National Development and Reform Commission. International Energy Agency. China Wind Energy Development Roadmap 2050; Technical Report; Energy Research Institute: Beijing, China, 2011.

4. Xia, C.; Song, Z. Wind energy in China: Current scenario and future perspectives. Renew. Sustain. Energy Rev. 2009, 13, 1966-1974.

5. Sun, L.H.; Ai, W.X.; Song, W.L.; Wang, Y.M. Study on climatic characteristics of China-influencing tropical cyclones. J. Trop. Meteorol. 2011, 17, 181-186.

6. An, Y.; Quan, Y.; Gu, M. Field measurement of wind characteristics of typhoon muifa on the Shanghai world financial center. Int. J. Distrib. Sens. Netw. 2012, 8, 893739. [CrossRef] 
7. Mostafaeipour, A. Feasibility study of offshore wind turbine installation in Iran compared with the world. Renew. Sustain. Energy Rev. 2010, 14, 1722-1743. [CrossRef]

8. Ochieng, E.G.; Melaine, Y.; Potts, S.J. Future for offshore wind energy in the United Kingdom: The way forward. Renew. Sustain. Energy Rev. 2014, 39, 655-666. [CrossRef]

9. Colmenar-Santos, A.; Perera-Perez, J.; Borge-Diez, D. Offshore wind energy: A review of the current status, challenges and future development in Spain. Renew. Sustain. Energy Rev. 2016, 64, 1-18. [CrossRef]

10. Breton, S.P.; Moe, G. Status, plans and technologies for offshore wind turbines in Europe and North America. Renew. Energy 2009, 34, 646-654. [CrossRef]

11. Bilgili, M.; Yasar, A.; Simsek, E. Offshore wind power development in Europe and its comparison with onshore counterpart. Renew. Sustain. Energy Rev. 2011, 15, 905-915. [CrossRef]

12. Chehouri, A.; Younes, R.; Ilinca, A. Review of performance optimization techniques applied to wind turbines. Appl. Energy 2015, 142, 361-388. [CrossRef]

13. Fingerish, L.; Hand, M.; Laxson, A. Wind Turbine Design Cost and Scaling Model; Technical Report; National Renewable Energy Laboratory: Golden, CO, USA, 2006.

14. Fuglsang, P.; Madsen, H. A. Numerical optimization of wind turbine rotors. In Proceedings of the European Union Wind Energy Conference, Göteborg, Sweden, 20-24 May 1996; pp. 679-682.

15. Wang, X.; Shen, W.Z.; Zhu, W.J. Shape optimization of wind turbine blades. Wind Energy 2009, 12, 781-803.

16. Vesel, R.W., Jr.; Mcnamara, J.J. Performance enhancement and load reduction of a 5 MW wind turbine blade. Renew. Energy 2014, 66, 391-401. [CrossRef]

17. Fuglsang, P.; Thomsen, K. Site-specific design optimization of 1.5-2.0 MW wind turbines. J. Sol. Energy Eng. 2001, 123, 296-303. [CrossRef]

18. Barnes, R.H.; Morozov, E.V. Structural optimisation of composite wind turbine blade structures with variations of internal geometry configuration. Compos. Struct. 2016, 152, 158-167. [CrossRef]

19. Jureczko, M.; Pawlak, M.; Mężyk, A. Optimisation of wind turbine blades. J. Mater. Process. Technol. 2005, 167, 463-471. [CrossRef]

20. Buckney, N.; Pirrera, A.; Green, S.D. Structural efficiency of a wind turbine blade. Thin Walled Struct. 2013, 67, 144-154. [CrossRef]

21. Pirrera, A.; Capuzzi, M.; Buckney, N.; Weaver, P.M. Optimization of Wind Turbine Blade Spars. In Proceedings of the 53rd AIAA/ASME/ASCE/AHS/ASC Structures, Structural Dynamics, \& Materials Conference, Honolulu, HI, USA, 23-26 April 2012.

22. Ye, Z.; Liu, X.; Chen, Y. Global Optimum Design Method and Software for the Rotor Blades of Horizontal Axis Wind Turbines. Wind Eng. 2002, 26, 257-269. Available online: http://dx.doi.org/10.1260/ 030952402321039449 (accessed on 05 March 2017).

23. Liu, X.; Chen, Y.; Ye, Z. Optimization model for rotor blades of horizontal axis wind turbines. Front. Mech. Eng. China 2007, 2, 483-488. [CrossRef]

24. Gutierrez, C.R. Aerodynamic and Aeroelastic Design of Low Wind Speed Wind Turbine Blades. Master's Thesis, Delft University of Technology, Delft, The Netherlands, 2014.

25. Zhu, J.; Cai, X.; Gu, R. Aerodynamic and Structural Integrated Optimization Design of Horizontal-Axis Wind Turbine Blades. Energies 2016, 9, 66. [CrossRef]

26. Meng, G.; Jicai, N.; Wu, X. Normal and Extreme Wind Conditions for Power at Coastal Locations in China. PLOS ONE 2015, 10, e0136876.

27. Silva, J.; Ribeiro, C.; Guedes, R. Roughness Length Classification of Corine Land Cover Classes. In Proceedings of the European Wind Energy Conference \& Exhibition (EWEC) 2007; MEGAJOULE Consultants, Milan, Italy, 7-10 May 2007.

28. International Standard IEC 61400-1: Wind Turbine-Part 1: Design Requirements, 3rd ed.; International Electrotechnical Commission: Geneva, Switzerland, 2005.

29. Piegl, L.; Tiller, W. The NURBS Book, 2nd ed.; Springer: New York, NY, USA, 1997.

30. Jonkman, J.; Butterfield, S.; Musial, W.; Scott, G. Definition of a 5-MW Reference Wind Turbine for Offshore System Development; National Renewable Energy Laboratory: Golden, CO, USA, 2009.

31. Ramos-García, N.; Sørensen, J.N.; Shen, W.Z. A strong viscous-inviscid interaction model for rotating airfoils. Wind Energy 2013, 17, 1957-1984. [CrossRef]

32. Viterna, L.A.; Janetzke, D.C. Theoretical and Experimental Power from Large Horizontal-Axis Wind Turbines; NASA Lewis Research Center: Cleveland, OH, USA, 1982. 
33. Øye, S. FLEX4 simulation of wind turbine dynamics. In Proceedings of the 28th IEA Meeting of Experts Concerning State of the Art of Aeroelastic Codes for Wind Turbine Calculations, Lyngby, Denmark, 11-12 April 1996.

34. Bir, G.S. User's Guide to PreComp: Pre-Processor for Computing Composite Blade Properties; National Renewable Energy Laboratory: Golden, CO, USA, 2005.

35. Jonkman, J.M.; Buhl, M.L. FAST User's Guide; National Renewable Energy Laboratory: Golden, CO, USA, 2005.

36. Larsen, T.J.; Hansen, A.M. HAWC2-User Manual; Technical University of Denmark: Lyngby, Denmark, 2007.

37. Hasen, M.O.L.; Sorensen, J.N.; Voutsinas, S.; Sorensen, N.; Madsen, H.A. State of the art in wind turbine aerodynamics and aeroelasticity. Prog. Aerosp. Sci. 2006, 42, 285-330. [CrossRef]

38. Borg, M.; Bredmose, H. Qualification of Innovative Floating Substructures for $10 \mathrm{MW}$ Wind Turbines and Water Depths Greater Than 50 m. Deliverable D4.4-Overview of the Numerical Models Used in the Consortium and Their Qualification; Technical Report DTU Wind Energy E-0097; Technical University of Denmark: Lyngby, Denmark, 2015.

39. Sessarego, M.; Ramos-Garcia, N.; Sorensen, J.N.; Shen, W.Z. Development of an aeroelastic code based on three-dimensional viscous-inviscid method for wind turbine computations. Wind Energy 2017. [CrossRef]

40. Blasques, J.P.; Stolpe, M. Multi-material topology optimization of laminated composite beam cross sections. Compos. Struct. 2012, 94, 3278-3289. [CrossRef]

41. Yu, W.; Hodges, D.H.; Ho, J.C. Variational asymptotic beam sectional analysis-An updated version. Int. J. Eng. Sci. 2012, 59, 40-64. [CrossRef]

42. Ning, A.; Damiani, R.; Moriarty, P.J. Objectives and constraints for wind turbine optimization. J. Sol. Energy Eng. 2014, 136, 041010. [CrossRef]

43. Bir, G.S. User's Guide to BModes: Software for Computing Rotating Beam Coupled Modes; National Renewable Energy Laboratory: Golden, CO, USA, 2007.

44. Hansen, M.O.L. Aerodynamics of Wind Turbines, 2nd ed.; Earthscan: London, UK, 2008.

45. Sessarego, M.; Ramos-García, N.; Shen, W.Z.; Sørensen, J.N. Large wind turbine rotor design using an aero-elastic/free-wake panel coupling code. J. Phys. Conf. Ser. 2016, 753, 042017. [CrossRef]

46. Sessarego, M.; Ramos-García, N.; Yang, H.; Shen, W.Z. Aerodynamic wind-turbine rotor design using surrogate modeling and three-dimensional viscous-inviscid interaction technique. Renew. Energy 2016, 93, 620-635. [CrossRef]

47. MATLAB 2014b; The MathWorks Inc.: Natick, MA, USA, 10 October 2014.

48. Chow, R. Computational Investigations of Inboard Flow Separation and Mitigation Techniques on Multi-Megawatt Wind Turbines. Ph.D. Thesis, University of California Davis, Davis, CA, USA, 2011.

49. Sale, D.C. Northwest National Renewable Energy Center, Department of Mechanical Engineering. In User's Guide to Co-Blade: Software for Structural Analysis of Composite Blades; University of Washington: Seattle, WA, USA, 2012.

50. Joncas, S.; de Ruiter, M.J.; van Keulen, F. Preliminary design of large wind turbine blades using layout optimization techniques. In Proceedings of the 10th AIAA/ISSMO multidisciplinary analysis and optimization conference, Albany, NY, USA, 30 August-1 September 2004.

51. Resor, B.R. Definition of a 5 MW/61.5 m Wind Turbine Blade Reference Model; Sandia National Laboratories: Albuquerque, NM, USA, 2013.

52. Shi, Y. Particle swarm optimization: Developments, applications and resources. In Proceedings of the 2001 Congress on Evolutionary Computation, Seoul, Korea, 27-30 May 2001; Volume 1, pp. 81-86.

(C) 2017 by the authors. Licensee MDPI, Basel, Switzerland. This article is an open access article distributed under the terms and conditions of the Creative Commons Attribution (CC BY) license (http://creativecommons.org/licenses/by/4.0/). 